The UCT class of 2000 reunion

To the Editor: It was with mixed emotions that we prepared for our 15-year reunion at the University of Cape Town in November 2015. Certainly the nationwide student protests and shutdowns made administration and organisation quite challenging, but they also gave us a chance to reflect on our own medical education and training. As graduates of UCT in 2000, we started our professional careers as young interns in the middle of the HIV epidemic. As medical students we joked about including HIV or TB on every differential list, but as young doctors it was no longer a joke but a grim reality. With no antiretrovirals to offer our patients, a limited supply of fluconazole and Bactrim and HIV ELISA results that took 6 weeks to return from a tertiary centre, we found ourselves signing piles of death certificates every week and standing helplessly in front of our patients despite having been trained as curative clinicians.

In the 15 years since our graduation, medical education has been challenged with providing training that is socially relevant to the community served by its graduates. More recent competencybased education models are promoting additional roles for graduate doctors not only as medical experts but also as health advocates, collaborators, communicators and leaders. The outcomes are clear, but the mechanisms to teach these attitudes and skills are still debated.

As part of our reunion weekend, not only did we have time for social conversations and sharing family time in the beautiful gardens 
of Kirstenbosch, but we also facilitated an 'academic meeting' on the Saturday morning. The purpose of this meeting was to share our experiences over the past 15 years and reflect on the varied paths we had chosen after graduation: from the prescribed internship and community service year, to working overseas, to specialising and sub-specialising, and how that journey had been different for each person, with unique challenges that moulded our decision-making and career choices.

Somehow amid the chaos of being young, naive interns in communities devastated by HIV, our classmates had emerged as leaders, communicators, collaborators and health advocates. We heard how not even an $\mathrm{MB} \mathrm{ChB}$ and an MBA degree can provide immunity against feelings of loneliness and uncertainty in one's skills to perform the required job, that scholarship is lifelong, and that leaders are people who rise to a challenge. We were challenged to observe the world through different-coloured lenses and see the unique contribution that each individual can make, and to define ourselves as people rather than as doctors. We heard how the nightmare of the London tube bombings in 2005 would call to action years of clinical training and create leaders within minutes. We heard from advocates who not only promoted the plight of their individual patients, but are working daily to make a change and improve healthcare for their entire community. We observed the love and empathy of a small team that grew into a big team through collaboration and leadership to provide excellent healthcare for a small rural community.

Many of our class had specialised, some remained in general practice; some were working in tertiary academic or government practice and others in private practice. Some were working overseas, but over half of the class had returned to or remained in South Africa. Many of the class have also excelled in spheres of life outside medicine, travelled the globe, and been blessed with the joys of having a family.

In reflecting on this milestone achievement of 15 years since graduation, perhaps these anecdotes provide some insight as to how change can be effected. At the time of our graduation we were eager to make a difference to healthcare in South Africa, armed with limited knowledge, skills and fledgeling critical thinking ability. It seems that even without overt exposure to a competency-based, graduate attributesdriven curriculum, the class of 2000 have emerged as 'change agents' in healthcare and their communities. As the first doctors of the 21st century (dubbed the 'Millennium Medics' by Prof. Immelman) we were going to make history anyway!

\section{Paula Diab}

Discipline of Rural Health, School of Nursing and Public Health, University of KwaZulu-Natal, Durban, South Africa

diabp@ukzn.ac.za

\section{Angela Dramowski}

Department of Paediatrics and Child Health, Faculty of Medicine and Health Sciences, Stellenbosch University, Tygerberg, Cape Town, South Africa

\section{Nienke van Schaik}

Health Systems Trust, Cape Town, South Africa

\section{S Afr Med J 2016;106(2):129-130. DOI:10.7196/SAMJ.2016.v106i2.10449}

\section{Correction}

In the article 'Using mobile technology to improve maternal, child and youth health and treatment of HIV patients' by Peter et al., which appeared on pp. 3 - 4 of the January 2016 SAMJ, the USSD number was given as ${ }^{\star} 150^{\star} 550 \#$, which is incorrect. The number is in fact ${ }^{*} 134^{\star} 550 \#$, and anyone dialling the ${ }^{\star} 150^{\star}$ number to test the service will receive a message saying the service is not running. The online version of the article (http://dx.doi.org/10.7196/SAMJ.2016.v106i1.10209) was corrected on 7 January 2016.

\section{This month in the $S A M J \ldots$}

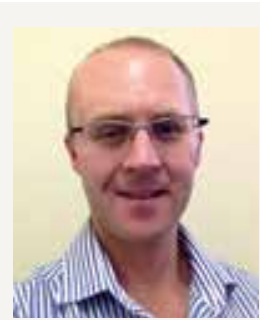

Jerome Loveland ${ }^{*+*}$ is Academic Head of Paediatric Surgery, University of the Witwatersrand, Clinical Head of Paediatric Surgery at Chris Hani Baragwanath Academic Hospital, and an Associate Professor in the School of Clinical Medicine, University of the Witwatersrand. He is also a senior member of the Transplant Unit at Wits Donald Gordon Medical Centre. His specific clinical interests in paediatric surgery include hepatobiliary disease, oncology and neonatal and laparoscopic surgery, as well as hepatic and renal transplantation. In addition to his clinical work, he has a keen interest in clinical research in both paediatric surgery and transplantation, and is committed to developing this field at Wits University. Outside of his career, Jerome is a committed family man, supported by his wife and children. His mental battles are fought while running ...

*Patel N, Naidoo P, Smith M, Loveland J, Govender T, Klopper J. South African surgical registrar perceptions of the research project component of training: Hope for the future? S Afr Med J 2016;106(2):169171. [http://dx.doi.org/10.7196/SAMJ.2016.v106i2.10310]

'Fabian J, Maher H, Bentley A, et al. Favourable outcomes for the first 10 years of kidney and pancreas transplantation at Wits Donald Gordon Medical Centre, Johannesburg, South Africa. S Afr Med J 2016;106(2):172-176. [http://dx.doi.org/10.7196/SAMJ.2016.v106i2.10190]

Carapinha C, Truter M, Bentley A, Welthagen A, Loveland J. Factors determining clinical outcomes in intussusception in the developing world: Experience from Johannesburg, South Africa. S Afr Med J 2016;106(2):177-180. [http://dx.doi.org/10.7196/SAMJ.2016.v106i2.9672]

${ }^{\S}$ Jugmohan B, Loveland J, Doedens L, Westgarth-Taylor CJ. Mortality in paediatric burns victims: A retrospective review from 2009 to 2012 in a single centre. S Afr Med J 2016;106(2):189-192. [http://dx.doi. org/10.7196/SAMJ 2016.v106i2.8942]

June Fabian* is a specialist physician and nephrologist, currently doing clinical research at Wits Donald Gordon Medical Centre. 